\title{
Teaching Engineering Ethics Through a Psychology Course
}

\author{
https://doi.org/10.3991/ijep.v11i1.14999 \\ Nguyen Van Hanh ${ }^{(凶)}$, Nguyen Tien Long \\ Hanoi University of Science and Technology, Hanoi, Vietnam \\ Hanh.nguyenvan@hust.edu.vn \\ Nguyen Thi Duyen, Phan Thi Thanh Canh \\ Hungyen University of Technology and Education, \\ Hungyen, Vietnam \\ Nguyen Thanh Long \\ Hanoi Architectural University, Hanoi, Vietnam \\ Mai Duc Thang \\ Ho Chi Minh City University of Technology, \\ Ho Chi Minh City, Vietnam
}

\begin{abstract}
While ethics instruction is now widespread, studies are still looking for different ways to integrate ethics in engineering programs. In this article, we propose a novel approach by teaching engineering ethics through a psychology course. Starting with the relevant literature studies, we have argued that the phenomenological experience of ethics is a source to explain psychological truths, while engineering ethics can be better taught from psychological / behavioral perspectives. A pedagogical approach of experiential learning has been applied to integrate engineering ethics into the psychology course. The empirical study with 400 students in psychology courses show that teaching engineering ethics through a psychology course has a significant effect on improving the knowledge of engineering ethics for students. The relationship between the pre and post test scores is a strong positive linear relationship. A regression equation with a slope of a straight line of 0.57 and a constant of 1.52 has been provided to predict the improvement of post-test scores through pre-test scores. This study proposes the formation of a "psychology and ethics" module in technical schools.
\end{abstract}

Keywords - Experiential learning, engineering ethics, psychology course, professional responsibility, teaching engineering ethics

\section{$1 \quad$ Introduction}

Since engineering ethics became an accreditation criteria for the engineering program, they have created a growing interest among universities on the issue of increasing the ethical knowledge among their students and the production of ethically responsible 
engineers [1]. Nowadays, engineering ethics is an integral part of engineering education $[14,19,22,24]$, such as a stand-alone course in engineering ethics [5], teaching ethics across the engineering curriculum [11]. The studies of ethics are of central importance for engineering education [12]. Some studies imply that students attending an ethics course or module are more likely to realize the core value of an ethical issue in a more complex situation than students who have not had previous experience [1]. However, students find it difficult to make judgments about human relations in the ethical cases [23]. They also know that the human relations behind the case make ethical matters more complicated [23]. This implies that the psychological factors have an influence on engineer ethics education.

In Vietnam, engineering ethics is not yet an accreditation criteria for engineering education programs, as a requirement necessary to make engineering schools change their perceptions and to have a pressure to integrate engineering ethics into their engineering program. The engineering schools, along with their lecturers, are also not fully aware of the importance of engineering ethics education, when their programs are filled or overloaded with technical courses. Typically, Hanoi University of Science and Technology (HUST), a prestigious engineering university in Vietnam, also has a lack of engineering ethics in its engineering programs. As HUST member lecturers, we feel the need to have a professional responsibility in teaching engineering ethics to our students. But, how? We cannot establish free courses of ethics because of the difficulties of using lecture halls at our institution, and we are not sure whether students are willing to participate. Our colleagues are also not willing to integrate engineering ethics into their technical courses. Finally, we came up with a novel idea: "why don't we integrate engineering ethics into our module - that's Psychology". Therefore, the purpose of this empirical study is to explore the effects of teaching engineering ethics through a psychology course.

\section{Theoretical Framework}

\subsection{What is engineering ethics?}

It may be redundant if we try to reiterate the definitions of engineering ethics that have been recognized in previous studies. In this section, we try to present different interpretations of the concept of engineering ethics, and more broadly, an engineering ethics course. That helps us position the approach in this study.

Previous studies agreed that ethics "is the set of moral ideals shared by most members of a culture or society" [2] (p. 25). The word "ethics" in English is understood in three senses, it can be (1) a synonym for ordinary morality, (2) a field of philosophy, or (3) a set of special ethically permissible standards [7-8]. When we are young, we learn more about ordinary morality, such as not killing people, not lying, not cheating, keeping promises. They are the same for everyone, engineers included. In the second sense, when a field of philosophy provides a course of engineering ethics, it will help students try to understand those special standards by using the rational justification for morality [8]. Such a course will try to connect engineering's ethical issues with philosophical 
origins, such as atheism theory. In the third sense, "engineering ethics" refers to the special ethical standards that every engineer should follow in professional practice [8]. In these courses (in the third sense), engineering ethics is like a collaborative practice [8], where special standards seem to dominate discussions and debate of ethics among members of the engineering profession. In this article, we have applied the concept of engineering ethics in the third sense.

\subsection{Interaction of psychology and ethics}

The quality of literature reviews on the interaction between psychology and ethics play a decisive role in the academic achievement of this study. Therefore, the literature search process is very important to enhance the rigor of the subsequent literature analysis. The Boolean combination of the search keywords was used to conduct literature searches in the Google Scholar database. In which, the code 'AND' was used to combine a keyword 'psychology' with a keyword 'ethics' or 'engineering ethics'. Peerreviewed studies available in English are selected when they meet one of the following three criteria: (1) explaining the interaction of psychology and ethics; (2) explaining ethical phenomena by psychology, or vice versa; (3) teaching ethics from a psychological / behavioral perspective, or vice versa. Based on these criteria, we selected six good quality studies, including five articles and one book chapter ([3], [6], [9], [10], [13] and [16] in the list of references). All of these articles are in the Web of Science by Clarivate Analytics. However, we did not find any literature on the subject of teaching engineering ethics through a psychology course. This means our empirical work is an original study.

The review of literature shows that psychological processes significantly affect people's interpretations and ultimately their behaviors, among them 'ethical behavior' [9]. The relationship between psychology and ethics is interaction and conflict [16]. While ethical values originate and become the responsibilities of a democratic society, not of psychology, but the phenomenological experience of ethics is a source to explain psychological truths [16]. Some studies agree that knowledge of facts, they presuppose knowledge of ethical values, and the judgments of those values may be objectively right [3]. In this view, the objects of psychology can be accurately described only with value concepts, among them thick ethical values [3]. In other words, the objectivity of ethical facts can be discovered by psychology. In addition, individuals tend to regard ethical principles as objective, and they also tend to treat ethical beliefs as objectively when they grounded their ethical systems [13]. This means that ethical facts can be used as teaching materials of a psychology course.

Teaching ethics from the perspective of behavioral / psychological science should not be considered new, but it has not yet been applied in the field of engineering ethics. A scholar declared quite bluntly: "Responsibility professors who ignore the psychological underpinnings of moral reasoning are plainly guilty of educational malpractice" [6] (p. 268-269). Many scholars call for a pedagogical approach that incorporates behavioral / psychological lessons into the ethical responsibility curriculum, or vice versa [10]. The diverse use of experiential techniques can immerse students in the contexts and emotions of ethical behavioral practices, which provide a detailed model of ethical 
teaching from a behavioral / psychological [10]. Thus, the central concepts from behavioral / psychological science can be embedded in discussions to illuminate ethical disputes, while psychological truths can be explained through ethical behavior.

\subsection{Pedagogical approach: Experiential learning}

To integrate engineering ethics into the psychology course, the researchers used experiential learning theory of Kolb [18]. Kolb noted that knowledge is created in a transformation process of experiences [18]. This leads researchers to the idea of using ethical dilemmas as teaching materials to teach psychology, in which psychological knowledge is created by reflecting the ethical experience of students. We modified Kolb's model for teaching engineering ethics through a psychology course (Figure 1).

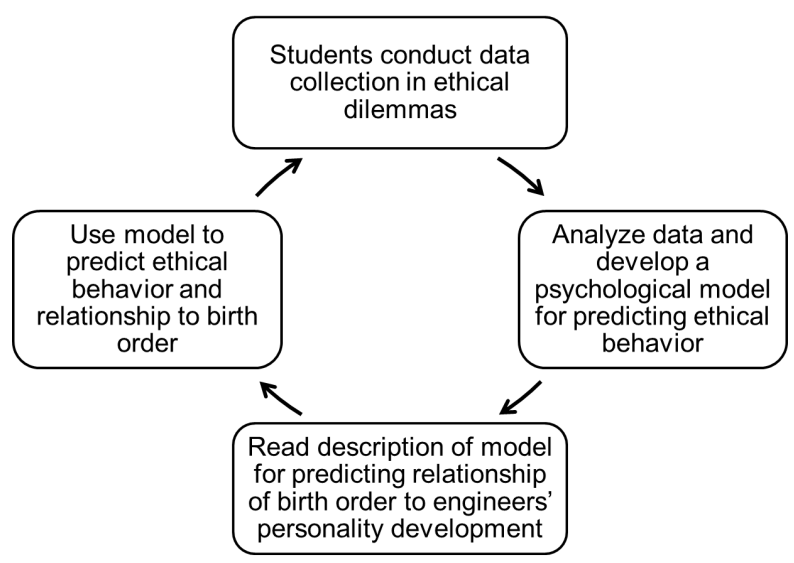

Fig. 1. Modified Kolb's learning cycle for teaching engineering ethics through a psychology course

The first phase - Students conduct data collection in ethical dilemmas: Students encounter new ethical dilemmas or reiterate existing ethical experiences. Based on NSPE Code of Ethics for Engineers [20], students discuss / debate to generate the order of ethical behavior of engineers. The students' ethical problem-solving process is guided in four tasks designed by Keefer et al. [15]. From there, they perform data collection on the psychological factors affecting the ethical behavior of engineers. In essence, lecturers have used the ethical dilemmas as a source for students to explore psychological truths. Some basic psychological concepts are also introduced to the students in this phase.

The second phase - Analyze data and develop a psychological model for predicting ethical behavior: Based on the collected data, this phase is where students reflect deeply on what happened in ethical dilemmas. Based on the data collected, this phase is where students reflect more deeply on what happened in their ethical dilemmas. Students can participate in the discussion or ask themselves: What motivates engineers to have such ethical behavior? What are the main factors affecting engineers' 
personality development? From there, a psychological model for predicting the ethical behavior of engineers can be drawn by students.

The third phase - Read description of model for predicting relationship of birth order to engineers' personality development: This is a phase where students should read in depth psychology literature or consult colleagues to gain a better understanding and further ideas. Initially, students reinforce the psychological model that they have learned from the previous phase. After that, they try to find different ways to handle situations and think of strategies to encounter similar situations. Generally, by putting the whole process of ethical problem solving under the lens of psychology, students draw conclusions about the psychological theories behind ethical dilemmas.

Finally, the fourth phase - Use model to predict ethical behavior and relationship to birth order: Students apply new models / theories / knowledge in ethical practice to see what happens. Other ethical dilemmas are assigned to students to perform in individual or group activities.

At the end of the fourth phase, students return to the first phase to begin the next learning cycle, but with a higher level of understanding. Kolb's learning cycle is like a spiral without an end to help students continually revise their experience [18]. The knowledge gained in the previous learning cycle is the foundation for creating knowledge in the subsequent cycle.

From this, we defined four research hypotheses, including:

- Hypothesis 1 (H1): Experiential learning cycle is an effective pedagogical approach to integrating engineering ethics into behavioral psychology lessons.

- Hypothesis 2 (H2): Using ethical dilemmas in teaching psychology has a positive impact on the increase of students' knowledge of engineering ethics.

- Hypothesis 3 (H3): There is a significant relationship between the student's pre-and post-test scores for engineering ethics.

- Hypothesis 4 (H4): Students have positive feedback on teaching engineering ethics through a psychology course.

\section{$3 \quad$ Methodology}

At HUST, the "Psychology" module (code: ED 3280, and 2 credits) is designed as an elective module for all engineering students. The goal of the module is to help students apply psychological knowledge to explain behavioral phenomena in the field of engineering and engineering activities. Although it is an elective module, however, the number of technical students participating in learning is very large, up to 2500 students / semester. At the end of this psychology course, students are expected with three learning outcomes:

1) Understand fundamental knowledge of cognitive process

2) Apply the knowledge of human cognitive characteristics for industrial applications

3) Be able to consider rational and irrational aspects of humans 
The main topics of the course, including: (1) how psychology became science; (2) cognitive process; (3) attention; (4) emotions and affection; (5) memory; (6) decision making; (7) engineering's personality; (8) design thinking and systems thinking.

Positive discussions and critical thinking are appreciated in lectures. Small exercises / experiments are also introduced during the lectures to give students a deeper understanding of the topics. There are about 2 to 3 tests for formative assessment that are conducted through practical exercises / experiments. We have integrated the engineering ethics into two psychological topics at weeks 4 and 8 of a total of 15 weeks of the course, including: Cognitive process, emotions and affection. We do not integrate engineering ethics throughout a psychology course, because this makes students know that they are participating in an experimental program.

Materials in teaching engineering ethics are used in experimental programs, including:

1) NSPE Code of Ethics for Engineers [20]

2) Ethical case studies

3) Decision Procedure Checklist - DPC [15]

4) Decision Procedure Scoring Guide - DPSG [15]

In order to create a correlation between psychology and ethics, ethical cases were selected from NPSE's database resources based on the main criteria: (1) Suitable for many technical disciplines; (2) Psychological concepts that can support case studies; (3) Information of ethical cases can assist in learning psychological concepts. In each ethical topic, we have selected and used two ethical cases. One case was used as a teaching material for psychology, while the other one was used as an assessment tool. A total of four ethical cases corresponding to two psychological topics have been used (Please see the Appendix).

In the spring of 2020, an empirical study was conducted by researchers. There were 400 students of HUST in psychology classes that have been selected to participate in the experiment. Psychological lectures were conducted like other traditional lessons, except that the teaching materials used are ethical cases. In the practical part of the lesson, an ethical case was required for the individual student to complete a writing test in 45 minutes. Students are informed that their assignment will be assessed for a midterm score. The DPSG designed by Keefer et al. was used by us to score students' assignment [15]. All written tests collected were blindly scored by a colleague in our research team using the credit scale.

In addition, at the end of the experiment, a qualitative questionnaire was sent to students to collect their responses to teaching engineering ethics through a psychology course. We used the 5-point Liker scale for the following questions:

- Q1. I think the experience of engineering ethics is an interesting source to explain psychological truths.

- Q2. I believe that the NSPE code of ethics for engineers is important for fulfilling my responsibilities as a professional engineer.

- Q3. The discussion of ethical dilemmas helps me to better understand the meaning of NSPE code of ethics for engineers. 
- Q4. I learned psychological truths based on the information in the ethical case discussions.

- Q5. I find that psychological concepts / factors can help me explain more clearly in the dilemma of engineering ethics.

- Q6. I can apply the NSPE code of ethics for my decision-making process in ethical cases / exercises.

- Q7. I am more aware of the ways to solve ethical dilemmas and the consequences of ethical decisions from psychological insight.

- Q8. I believe that I will always act in accordance with this code of ethics.

These eight questions were designed by the researchers based on the learning cycle shown in Figure 1. Questions 1 and 8 correspond to the first phase - "students conduct data collection in ethical dilemmas". Questions 2 and 3 correspond to the second phase - "analyze data and develop a psychological model for predicting ethical behavior". Questions 4 and 5 correspond to the third phase - "read description of model for predicting relationship of birth order to engineers' personality development". Finally, question 6 and question 7 correspond to the fourth phase - "use model to predict ethical behavior and relationship to birth order".

\section{$4 \quad$ Results}

\subsection{Paired sample t-test}

The effect of teaching engineering ethics through a psychology course is measured by the pre- and post-test scores of 347 students. Accordingly, the paired sample t-test in the SPSS was conducted to determine whether there was a difference between the average of the pre- and post-test scores (Table 1).

Table 1. Paired Sample t-test for the data of teaching engineering ethics

\begin{tabular}{|l|c|c|c|c|c|c|}
\hline \multicolumn{1}{|c|}{ Group } & N & Mean & SD & Df & t & p \\
\hline Post-test & 347 & 3.23 & .42 & 346 & 11.425 & .00 \\
\cline { 1 - 4 } Pre-test & 347 & 3.01 & .56 & & & \\
\hline
\end{tabular}

The results in Table 1 , a value of $p=0.00(p<0.05)$ indicate a significant difference between the pre and post-test scores, which students did in ethical cases. The average of the pre-test scores was 3.01 at week 4, this average increased to 3.23 at week 8 of the total 15 weeks. In other words, teaching engineering ethics through a psychology course has a significant effect on improving the knowledge of engineering ethics for students. Thus, hypothesis $\mathrm{H} 2$ was supported.

\subsection{Normality analysis}

In the SPSS, histograms showing normal curves were drawn to find out whether data was normally distributed (Figure 2). The histogram of the pre-test score shows that the 
data was bell-shaped, the average value was 3.01 and the test scores were evenly distributed on both sides. Similarly, the histogram of the post-test score shows that the data was also bell-shaped, the average value was 3.23 and the test scores were evenly distributed on both sides. This implies that the ability of the pre- and post-test data of teaching engineering ethics were normally distributed.
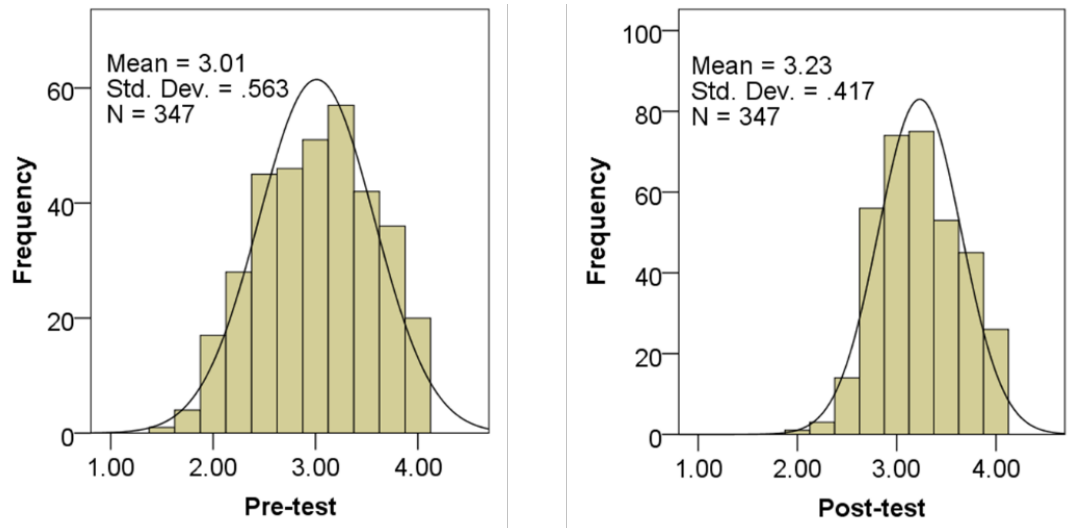

Fig. 2. Histograms of the pre- and post-test data

The Q-Q Plots of the two data as shown in Figure 2 also strengthened the findings of normality.
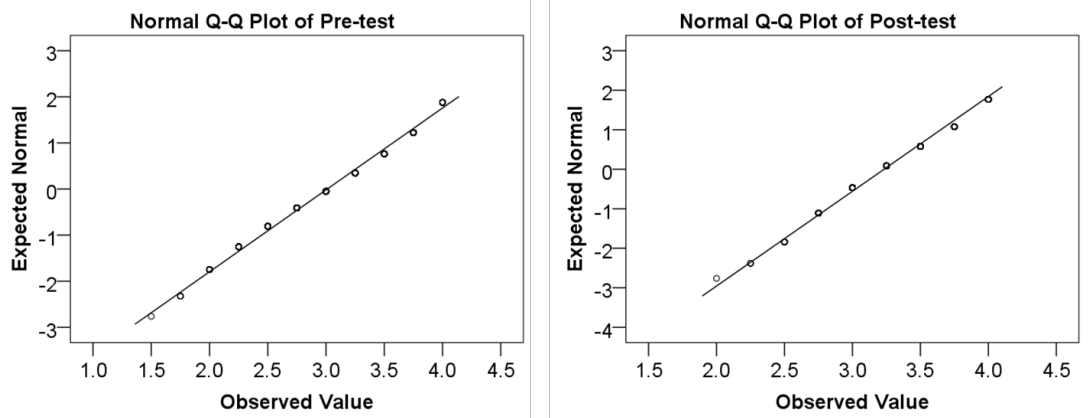

Fig. 3. Normal Q-Q plot of the pre- and post-test data

The results in Figure 3 show that most of the symbols were closer to the line and some of them were stick on it. Thus, the data of pre- and post-test scores on teaching engineering ethics were normally distributed. While Shapiro-Wilk test and Kolmogorov-Smirnov test may be used to confirm the normal distribution with small to medium sized samples (less than 300), they may be not reliable for large samples [17]. The skewness test and kurtosis test may be used to determine the normal distribution for the large sample size, such as $\mathrm{N}=347$ [17]. The results of the skewness test and kurtosis test were shown in Table 2. 
Table 2. Skewness test and Kurtosis test of the pre- and post-test data

\begin{tabular}{|l|c|c|c|c|c|}
\hline \multirow{2}{*}{} & \multirow{2}{*}{$\mathbf{N}$} & \multicolumn{2}{|c|}{ Skewness } & \multicolumn{2}{c|}{ Kurtosis } \\
\cline { 3 - 6 } & & Statistic & Std. Error & Statistic & Std. Error \\
\hline Pre-test & 347 & -.140 & .131 & -.736 & .261 \\
\hline Post-test & 347 & .061 & .131 & -.603 & .261 \\
\hline
\end{tabular}

Notes: The absolute value of the skewness was less than 2 and the absolute value of the kurtosis (proper) was less than 7 indicating that the data was certainly normally distributed [17]. In which, the SPSS test provides excess kurtosis by subtracting 3 from the proper kurtosis [17].

In all cases (Table 2), the absolute value of skewness was less than 2 and the absolute value of excess kurtosis was less than 4 indicating that the data was certainly normally distributed. In the data of pre-test score, a negative skew value of '- -0.14 ' indicates that the data distribution on the left was more than on the right. While in the data of posttest score, a positive skew value of ' 0.061 ' indicates that the data distribution on the right was more than on the left. In other words, the pre-test scores tend to be on the right of the mean (3.01), while the post-test scores tend to be on the left of the mean (3.23). In addition, the negative value of excess kurtosis in all cases were called platykurtic distribution which means flat-topped curve. In other words, it was difficult to have extreme scores in all data of the pre- and post-test of teaching engineering ethics through a psychology course.

\subsection{Linearity analysis}

The scatter plot of post-test scores with pre-test scores were drawn to find out whether data was linear. The complete test result is shown in Figure 4.

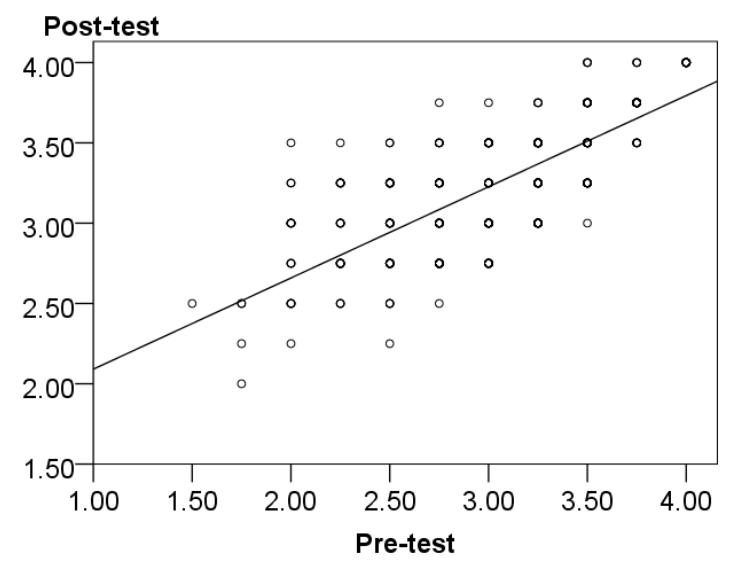

Fig. 4. Scatter plot of pre- and post-test scores data

The results in Figure 4 show that most of the symbols fell on or near a straight-line meaning the pattern was linear. The changing direction of post-test scores is increasing gradually with pre-test scores. This means that as the pre-test scores increases, so does 
post-test scores. Thus, the link between the pre- and post-test scores in teaching engineering ethics through a psychology course may be a strong positive linear relationship.

\subsection{Correlation analysis}

The Pearman test in the SPSS was conducted to find out whether the pre-post test scores were correlated (Table 3).

Table 3. Correlations between the pre- and post-test scores

\begin{tabular}{|l|c|c|c|}
\hline \multicolumn{2}{|c|}{} & Pre-test & Post-test \\
\hline Pre-test & $\mathrm{R}$ & 1 & $.767^{* *}$ \\
\cline { 2 - 4 } & $\mathrm{p}$ & & .000 \\
\cline { 2 - 4 } & $\mathrm{N}$ & 347 & 347 \\
\hline Post-test & $\mathrm{R}$ & $.767^{* *}$ & 1 \\
\cline { 2 - 4 } & $\mathrm{p}$ & .000 & 347 \\
\cline { 2 - 4 } & $\mathrm{N}$ & 347 & \\
\hline \multirow{2}{*}{$* *$. Correlation is significant at the 0.01 level (2-tailed) }
\end{tabular}

Notes: The minimum $R$ value is "0.5" (large effect size) as the expected level of the correlation between the pre- and post-test scores [4].

In Table 3, the p-value is 0.00 less than 0.05 and the $R$ value is 0.77 greater than 0.5 indicating a situation where a relationship of the pre-post test scores were acceptable. In other words, there was a significant correlation between the pre-post test scores of teaching engineering ethics through a psychology course.

\subsection{Regression analysis}

The linearity test in the SPSS test was conducted to find out whether the pre-post test scores were correlated (Table 4 and Table 5).

Table 4. Regression test result of pre- and post-test scores

\begin{tabular}{|c|c|c|c|c|c|}
\hline \multicolumn{6}{|c|}{ Model Summary $^{\mathbf{b}}$} \\
\hline Model & $\boldsymbol{R}$ & $\boldsymbol{R}$ Square & $\begin{array}{c}\text { Adjusted } \boldsymbol{R} \\
\text { Square }\end{array}$ & $\begin{array}{c}\text { Std. Error of the } \\
\text { Estimate }\end{array}$ & Durbin-Watson \\
\hline 1 & $0,767^{\mathrm{a}}$ & 0.588 & .586 & 5.395 & 1.822 \\
\hline $\begin{array}{l}\text { a. Predictors: (Constant), Pre-test } \\
\text { b. Dependent Variable: Post-test }\end{array}$
\end{tabular}

The results in Table 4 show $\mathrm{R} 2=0.59$ indicating that $59 \%$ of the post-test scores can be explained by pre-post test scores. In other words, the students' post test scores was $59 \%$ influenced by their pre-post test scores. Whereas, the rest $(41 \%)$ was influenced by other factors. In addition, the Durbin-Watson value of 1.822 was in the range of "1.758" (du) to "4 - 1.747 = 2.253" (4-dl) (with dl and du from Durbin-Watson Table, Alpha $=0.01)$, indicating that the autocorrelation problem in regression analysis was rejected. Thus, hypothesis H3 was supported. 
Table 5. Correlation coefficient test result of pre- and post-test scores data

\begin{tabular}{|c|c|c|c|c|c|c|}
\hline \multicolumn{7}{|c|}{ Coefficients $^{\mathrm{a}}$} \\
\hline \multicolumn{2}{|c|}{ Model } & $B$ & Std. Error & Beta & $t$ & Sig. \\
\hline \multirow[t]{2}{*}{1} & (Constant) & 1.523 & .078 & & 19.424 & .000 \\
\hline & Pre-test & .568 & .026 & .767 & 22.173 & .000 \\
\hline
\end{tabular}

The results in Table 5 show that the slope of a straight line was "0.57" and the constant was "1.52". Thus, the relationship between pre-test scores $(\mathrm{X})$ and post-test scores (Y) was: $\mathbf{Y}=\mathbf{1 . 5 2}+\mathbf{0 . 5 7} \mathbf{X}$. This equation shows that if $\mathrm{Y}$ equals "4" then $\mathrm{X}$ equals "4.35". In other words, to help learners achieve the maximum score of the credit scale (score 4), we will integrate the ethical cases into at least four psychological topics. Thus, hypothesis H1 was supported. Figure 5 shows the result of the regression line of teaching engineering ethics through a psychology course.

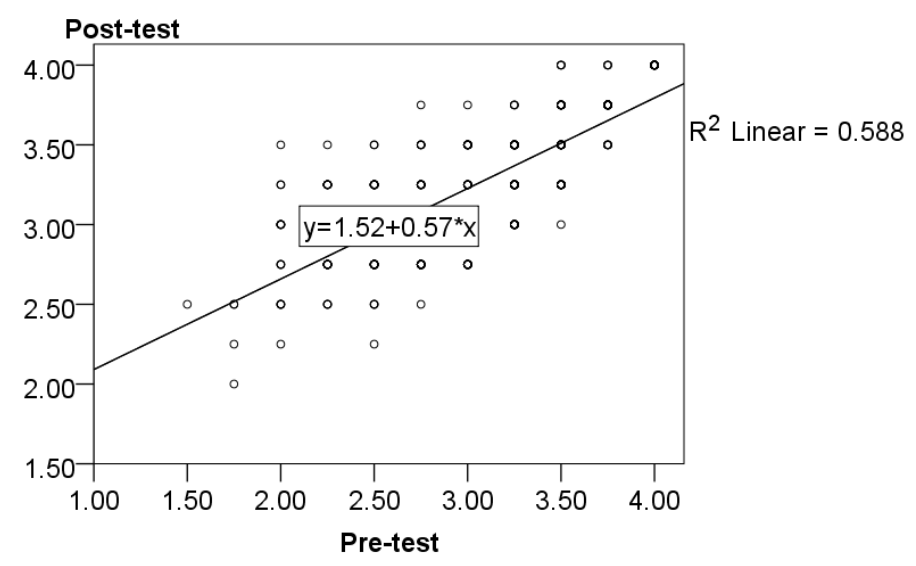

Fig. 5. Regression line result

\subsection{Student feedback}

A total of 340 questionnaires collected were valid when no questions were left blank. In the SPSS, eight histograms were drawn to observe the distribution of student feedback on teaching engineering ethics through a psychology course (Figure 6). 

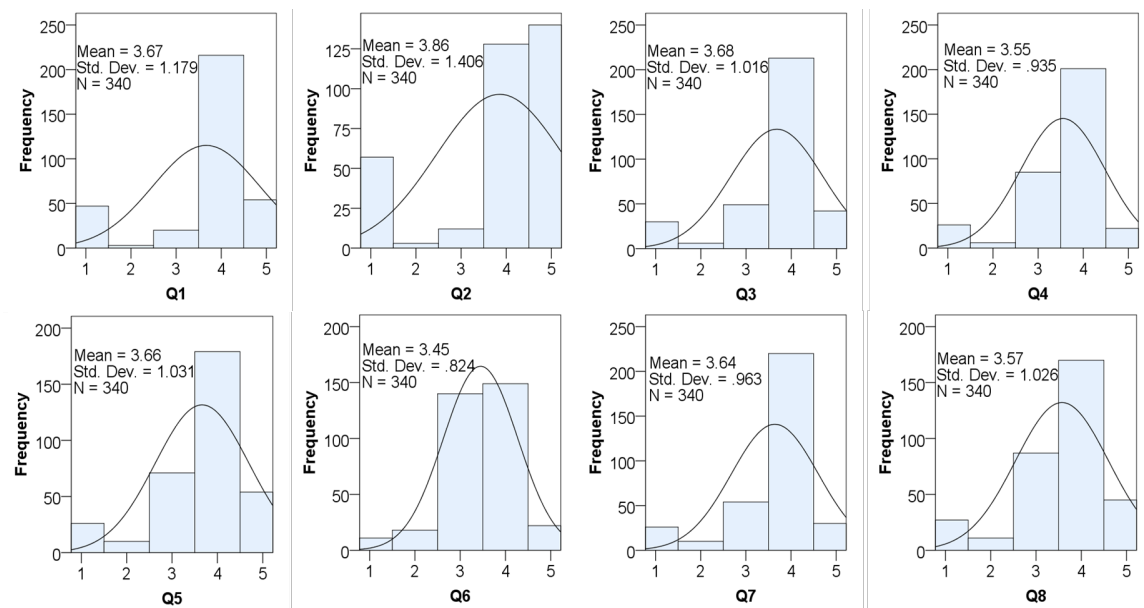

Fig. 6. Histograms of student feedback

Notes: The range of 1 to 5 is represented by "strongly disagree" to "strongly agree". We used the mean scoring technique designed by Sarrafzadeh et al., with ranges from 1 to $1.44=$ Strongly disagree, 1.45 to $2.44=$ Disagree, 2.45 to $3.44=$ Neutral; 3.45 to $4.44=$ Agree; 4.45 to $5=$ Strongly agree. A cut of 3.45 was selected as the minimum score for "Agree" or above [21].

In the results of Figure 6, the mean values of observed variables were greater than the minimum score of "3.45" (Agree level) indicating the success of teaching engineering ethics through a psychology course. The distribution of data on student feedback in questions Q1, Q3, Q4, Q5, Q6, Q7 and Q8 has a peak at 4 = "agree". Interestingly, the distribution of data on student feedback in questions Q2 has a peak at 5 = "strongly agree". In other words, students strongly believe that the NSPE code of ethics for engineers is important for fulfilling my responsibilities as a professional engineer. Surprisingly, except for question Q6, the distribution of data on student feedback for level 1 (strongly disagree) is higher than level 2 (disagree). Especially in question Q2, 57/340 $(16.8 \%)$ students do not think that the NSPE code of ethics for engineers is important for fulfilling my responsibilities as a professional engineer. In question Q1, 47/340 $(13.8 \%)$ students do not think that the experience of engineering ethics is an interesting source to explain psychological truths. Surprisingly, when observing the student feedback for level 1 of questions Q1 and Q2, up to 29 responses were coincidental. Although the distribution of student feedback for level 1 (strongly disagree) is small compared to the totals for levels 4 and 5 , it also shows that some students do not fully understand the engineering ethics.

The skewness test and kurtosis test in SPSS were used to conclude the normal distribution of the data on student feedback (Table 6). 
Table 6. Skewness test and Kurtosis test of the data on student feedback

\begin{tabular}{|l|c|c|c|c|c|}
\hline \multicolumn{1}{|c|}{ Items } & \multirow{2}{*}{$\mathbf{N}$} & \multicolumn{2}{c|}{ Skewness } & \multicolumn{2}{c|}{ Kurtosis } \\
\cline { 4 - 6 } & & Statistic & Std. Error & Statistic & Std. Error \\
\hline $\begin{array}{l}\text { Q1. I think the experience of engineering ethics is an } \\
\text { interesting source to explain psychological truths. }\end{array}$ & 340 & -1.405 & .132 & .979 & .264 \\
\hline $\begin{array}{l}\text { Q2. I believe that the NSPE code of ethics for engi- } \\
\text { neers is important for fulfilling my responsibilities as a } \\
\text { professional engineer. }\end{array}$ & 340 & -1.222 & .132 & .105 & .264 \\
\hline $\begin{array}{l}\text { Q3. The discussion of ethical dilemmas helps me to } \\
\text { better understand the meaning of NSPE code of ethics } \\
\text { for engineers. }\end{array}$ & 340 & -1.462 & .132 & 1.857 & .264 \\
\hline $\begin{array}{l}\text { Q4. I learned psychological truths based on the infor- } \\
\text { mation in the ethical case discussions. }\end{array}$ & 340 & -1.389 & .132 & 1.880 & .264 \\
\hline $\begin{array}{l}\text { Q5. I find that psychological concepts / factors can } \\
\text { help me explain more clearly in the dilemma of engi- } \\
\text { neering ethics. }\end{array}$ & 340 & -1.140 & .132 & 1.152 & .264 \\
\hline $\begin{array}{l}\text { Q6. I can apply the NSPE code of ethics for my deci- } \\
\text { sion-making process in ethical cases / exercises. }\end{array}$ & 340 & -.651 & .132 & 1.027 & .264 \\
\hline $\begin{array}{l}\text { Q7. I am more aware of the ways to solve ethical di- } \\
\text { lemmas and the consequences of ethical decisions from } \\
\text { psychological insight. }\end{array}$ & 340 & -1.503 & .132 & 2.050 & .264 \\
\hline $\begin{array}{l}\text { Q8. I believe that I will always act in accordance with } \\
\text { this code of ethics. }\end{array}$ & 340 & -1.031 & .132 & .904 & .264 \\
\hline
\end{tabular}

The results in Table 6 show that the absolute value of skewness was less than "2" and the absolute value of excess kurtosis was less than "4" indicating that the data on student feedback was certainly normally distributed. In all observed variables, the negative skew values indicate that the bulk of the data on student feedback lies to the right of the mean (mean $>=3.45$ ). Furthermore, distributions with positive excess kurtosis (leptokurtic distribution) means that the data on student feedback focused mainly on the score of 4 (agree) or 5 (strongly agree). In conclusion, student feedback was very positive for teaching engineering ethics through a psychology course. Thus, hypothesis H4 was supported.

\section{Discussion}

This research accomplishes the purpose to explore the effects of teaching engineering ethics through a psychology course. In our understanding, teaching engineering ethics through psychology is a novel method that has not been encountered in previous studies. The results of this study lead to four interesting discussions below.

Firstly, what was the novel approach in this research? Unlike the approach from previous studies, where ethics has tried to add to the technical courses that may be overloaded with knowledge. In this study, ethical values become teaching materials that enable students to acquire psychological knowledge, while also acquiring ethical knowledge. Clearly, the interaction between psychology and engineering ethics can help students simultaneously gain knowledge of both the content [16]. The reality of 
ethics are the facts of psychological phenomena, and conversely, psychological concepts are also important for resolving ethical disputes [13].

Second, the results of this study supplemented and contributed to the argument of many scholars about a pedagogical method that incorporates behavioral psychology lessons into the ethics course, and vice versa [10], in the field of engineering ethics education. In addition, this finding also supports the view of teaching engineering ethics from the perspective of behavioral psychology, which is implied in the reports of Daly [6] and Eldred [10]. Moreover, a pedagogical model has been developed to explain how engineering ethics are embedded in psychological lessons (Figure 1), which have not been found in previous studies. The effect of this model is clearly shown in the empirical results.

Third, the empirical results demonstrated that teaching engineering ethics through a psychology course has a significant effect on improving the knowledge of engineering ethics for students (Table 1). This result also shows that the relationship between the pre and post test scores is a strong positive linear relationship. The students' post test scores was $59 \%$ influenced by their pre-post test scores, while 59\% influenced by other factors. A regression equation with a slope of a straight line of 0.57 and a constant of 1.52 has been provided to predict the improvement of post-test scores through pre-test scores. The strength of this result is from the data of natural phenomena. Students are unaware that they are participating in an experimental program. They participated in discussions of ethical cases such as carrying out the tasks of psychological topics, because ethical cases were selected appropriately to learn psychological knowledge. In addition, students have never experienced engineering ethics courses before. Therefore, the increase in knowledge of students' engineering ethics is completely objective.

Fourth, finally, overall the student feedback was very positive for teaching engineering ethics through a psychology course. This result further supports the objectivity of the regression equation on the pre- and post-test data of teaching engineering ethics through a psychology course. The mean of all items was greater than the minimum average of "3.45" (Agree level). The distribution of data on student feedback in all observed variables has a peak at 4 (agree) or 5 (strongly agree). But surprisingly, except for question Q6, the distribution of data on student feedback for level 1 (strongly disagree) is higher than level 2 (disagree). Although this number is small but it also shows that some students do not fully understand the engineering ethics. These results lead to some questions that have not been clarified in this study. Why do some students underestimate the importance of engineering ethics? What are the attitudes toward engineering of those students and how does it affect engineering ethics? What are the attitudes toward psychology course of those students?

\section{Conclusion}

This study contributes in the existing literature a novel way to teach engineering ethics through a psychology course. The ethical values are used as teaching materials on psychological topics, through which ethical knowledge is transferred to students. The empirical results show that teaching engineering ethics through a psychology 
course has a significant effect on improving the knowledge of engineering ethics for students. This study also proposes the formation of a "psychology and ethics" module in technical schools.

\section{Acknowledgement}

This research is funded by Vietnam National Foundation for Science and Technology Development (NAFOSTED) under grant number 503.01-2019.01.

\section{$8 \quad$ References}

[1] Atesh, M., Ward, T., \& Baruah, B. (2016, September). Analyzing the perception, judgment and understanding of Ethics among Engineering students in Higher Education. In 2016 15th International Conference on Information Technology Based Higher Education and Training (ITHET) (pp. 1-7). IEEE. https://doi.org/10.1109/ithet.2016.7760702

[2] Barakat, N. (2011). Engineering ethics: A critical dimension of the profession. International Journal of Engineering Pedagogy, 1(2), 24-28. https://doi.org/10.3991/ijep.v1i2.1639

[3] Brinkmann, S. (2005). Psychology's facts and values: A perennial entanglement. Philosophical psychology, 18(6), 749-765. https://doi.org/10.1080/09515080500355244

[4] Cohen, J. (2013). Statistical power analysis for the behavioral sciences. Routledge.

[5] Cruz, J. A., Frey, W. J., Sanchez, H. D., \& Torres, M. A. (2004, October). Meeting the ethics challenge in engineering education: Re-accreditation and beyond. In 34th Annual Frontiers in Education, 2004. FIE 2004. (pp. S1E-15). IEEE. https://doi.org/10.1109/fie.2004. 1408694

[6] Daly, M. C. (2003). Teaching Integrity in the Professional Responsibility Curriculum: A Modest Proposal for Change. Fordham L. Rev., 72, 261.

[7] Davis, M. (1998). Thinking like an engineer. Studies in the Ethics of a Profession (book). 143. Oxford University Press.

[8] Davis, M. (2016). Teaching Ethics Across the Engineering Curriculum. Available at: https://www.onlineethics.org/Resources/instructessays/curriculum.aspx

[9] De Cremer, D. (2009). Psychology and ethics: What it takes to feel ethical when being unethical. In D. De Cremer (Ed.), Psychological perspectives on ethical behavior and decision making (p. 3-13). Information Age Publishing.

[10] Eldred, T. W. (2016). Insights from psychology: Teaching behavioral legal ethics as a core element of professional responsibility. Mich. St. L. Rev., 757. New England Law | Boston Research Paper No. 16-07. Available at SSRN: https://ssrn.com/abstract=2773777

[11] Fleischmann, S. T. (2004). Essential ethics - embedding ethics into an engineering curriculum. Science and Engineering Ethics, 10(2), 369-381. https://doi.org/10.1007/s11948 $\underline{-004-0033-5}$

[12] Freyne, S. F., Abulencia, J. P., \& Draper, P. (2011). Engineering and nonengineering students' perceptions of contemporary ethical issues. 2011 ASEE Annual Conference \& Exposition, Vancouver, BC (June 26-29, 2011), 22.576.1-22.576.19. https://peer.asee.org/ 17857. https://doi.org/10.18260/1-2--17857

[13] Goodwin, G. P., \& Darley, J. M. (2008). The psychology of meta-ethics: Exploring objectivism. Cognition, 106(3), 1339-1366. https://doi.org/10.1016/j.cognition.2007.06.007 
[14] Herkert, J. R. (2000). Engineering ethics education in the USA: Content, pedagogy and curriculum. European journal of engineering education, 25(4), 303-313. https://doi.org/10. $\underline{1080 / 03043790050200340}$

[15] Keefer, M. W., Wilson, S. E., Dankowicz, H., \& Loui, M. C. (2014). The importance of formative assessment in science and engineering ethics education: Some evidence and practical advice. Science and Engineering Ethics, 20(1), 249-260. https://doi.org/10.1007/ s11948-013-9428-5

[16] Kendler, H. H. (2002). Psychology and ethics: Interactions and conflicts. Philosophical psychology, 15(4), 489-508. https://doi.org/10.1080/0951508021000042030

[17] Kim, H. Y. (2013). Statistical notes for clinical researchers: assessing normal distribution (2) using skewness and kurtosis. Restorative dentistry \& endodontics, 38(1), 52-54. https://doi.org/10.5395/rde.2013.38.1.52

[18] Kolb, D. A. (1984). Experiential learning: Experience as the source of learning and development. New Jersey: Prentice-Hall.

[19] Monteiro, F. (2017). The Students' Perspective Contribution: Rethink the Ethical Education of Engineering Students. International Journal of Engineering Pedagogy, 7(2), 22-35. https://doi.org/10.3991/ijep.v7i2.6819

[20] National Society of Professional Engineers - NSPE (2019). NSPE Code of Ethics. Available at: https://www.nspe.org/sites/default/files/resources/pdfs/Ethics/CodeofEthics/NSPECode ofEthicsforEngineers.pdf. https://doi.org/10.1007/bf03223280

[21] Sarrafzadeh, M., Martin, B., \& Hazeri, A. (2010). Knowledge management and its potential applicability for libraries. Library Management, 31 (3), 198-212. https://doi.org/10.1108/01 435121011027363

[22] Stelios, S., \& Christodoulou, A. (2020). Teaching Professional Integrity: An Empirical Study on Engineering Students. International Journal of Engineering Pedagogy (iJEP), 10(3), 98-105. https://doi.org/10.3991/ijep.v10i3.12013

[23] Takahara, K., \& Kajiwara, T. (2013). Engineering ethics education on the basis of continuous education to improve communication ability. Electrical Engineering in Japan, 183(3), 602-607. https://doi.org/10.1002/eej.22283

[24] Wang, W. (2012). On the Status and Significance of Education on Engineering Ethics in Engineering Education. In Engineering Education and Management (pp. 441-446). Springer, Berlin, Heidelberg. https://doi.org/10.1007/978-3-642-24823-8_69

\section{Authors}

Nguyen Van Hanh (First author, Corresponding author 1) is a doctor of philosophy in education at School of Engineering Pedagogy, Hanoi University of Science and Technology, Vietnam. He graduated with a PhD in 2017 at the Hanoi National University of Education, Vietnam. His main research directions lie in the fields, including: theory and practice in engineering education, theory of educational technology, philosophy of engineering and technology, adult education, experiential education. He is currently the Editor in Chief of the Technology Textbook of the General Education Program in Vietnam after 2018.

Nguyen Tien Long (Corresponding author 2) is a doctor of mechanical engineering education. He is currently the deputy principal (vice-principal) of School of Engineering Pedagogy, Hanoi University of Science and Technology, Vietnam. His main research directions lie in the fields, including: Theory and practice in engineering 
education, practice of educational technology, adult education. Email: Long.nguyentien@hust.edu.vn

Nguyen Thi Duyen is a master of educational science, deputy head of the department of Engineering Pedagogy, Hungyen University of Technology and Education, Vietnam. His main research directions lie in the fields, including: Educational psychology, engineering pedagogy, and vocational education.

Phan Thi Thanh Canh is a master of educational science at the department of Engineering Pedagogy, Hungyen University of Technology and Education, Vietnam. His main research directions lie in the fields, including: Educational psychology, engineering pedagogy, and vocational education.

Nguyen Thanh Long is a doctor of educational science at Hanoi Architectural University, Vietnam. His main research directions lie in the fields, including: Mechanical engineering pedagogy, vocational education and architecture pedagogy.

Mai Duc Thang is a master of education management. He is currently the principal of high school, under Ho Chi Minh City University of Technology, Vietnam.

Article submitted 2020-04-20. Resubmitted 2020-06-24. Final acceptance 2020-06-24. Final version published as submitted by the authors. 


\section{$1 \quad$ Appendix}

Psychological topic: Cognitive process

Teaching material(s): Case 13-10 of NPSE

"Engineer A is an employee of Firm X. Engineer A prepares drawing, plans, reports, and specifications for Firm X clients. Engineer A maintains copies of drawings, plans, and specifications he has signed and sealed for his personal records in the event that Engineer A needs to refer to them at some point in the future (e.g., matters involving personal liability or professional liability). Thereafter, Engineer A leaves Firm X. Firm $\mathrm{X}$ learns of Engineer A's copies and demands that Engineer A return the copies to Firm $\mathrm{X}$, claiming the drawings, plans, reports, and specifications are the property of Firm $\mathrm{X}$. Engineer A refuses, claiming that he has a right to copies of his own work as illustrations of his work and in the event of future litigation or related matters." (https://www.nspe.org/sites/default/files/BER\%20Case\%20No\%2013-10-FINAL.pdf)

Assessment tasks: Case 18-5 of NPSE

"Engineer A, a professional engineer, worked for many years as a quality control engineer for Boilco, a boiler manufacturer. In recent years, Boilco began using a more economical international supplier of boiler valves and electric switches to reduce costs, but Engineer A's product testing demonstrated that the new boiler valves and electric switches were inferior and could be unsafe. Engineer A rejected the first shipment, but Engineer A's supervisor, also a professional engineer, overruled Engineer A. When Engineer A brought his product concerns to senior management, Engineer A's supervisor abruptly fired Engineer A for insubordination. After termination, Engineer A contacted a federal agency, detailing the threat to public safety posed by Engineer A's former employer."

(https://www.nspe.org/sites/default/files/BER18-5-APPROVED.pdf)

\section{Psychological topic: Emotions and affection}

Teaching material(s): Case 06-10 of NPSE

"Engineer $\mathrm{A}$, a quality assurance manager at Company $\mathrm{C}$, learns that the purchasing manager for Company $\mathrm{C}$ has contracted with a new supplier of precision plastic components. It turns out that the production manager at the new supplier is the quality assurance manager's spouse - a fact unknown to everyone at Company C. The quality assurance manager did not create this situation, and there is no effort to put pressure on any party in connection with the dealings between the parties."

(https://www.nspe.org/sites/default/files/resources/pdfs/Ethics/EthicsResources/EthicsCaseSear ch/2006/BER\%2006-10-FINAL.pdf)

\section{Assessment tasks: Case 66-5 of NPSE}

"John Doe, P.E., is the city engineer of a municipality. His duties include review of plans and specifications prepared for developers of housing projects, and recommendations to the city council on approval of such projects. Doe's wife has an investment in one of the development companies operating in the jurisdiction of the city, and plans for one of its projects were reviewed by him and approved by the city council. His 
wife's investment in the project was not known to the city officials or the public until after his review, recommendation for approval of the project and the approval of the city council. When the fact of his wife's investment was disclosed at a later date, Doe was requested to resign his position on the ground of unethical conduct."

(https://www.nspe.org/sites/default/files/resources/pdfs/Ethics/EthicsResources/EthicsCaseSear $\underline{\mathrm{ch} / 1966 / \mathrm{BER} \% 2066-5 . \mathrm{pdf})}$ 